\title{
Non-uniform factor of wind pressure calculation based on field measured data of incline angle of suspension string
}

\author{
Zhang Hong Jie ${ }^{1, a}$, Guo Jian Ping ${ }^{2}$, Gao Tong Shan ${ }^{2}$ and Zhao Qing Hua ${ }^{2, b}$ \\ ${ }^{1}$ China Electric Power Research Institute, Bei Jing, 100055, China \\ ${ }^{2}$ Xingtai Electric Power Company, Xingtai, 054001, China \\ azhanghongjie1@epri.sgcc.com.cn, ${ }^{b} 287880279 @ q q . c o m$
}

\begin{abstract}
Keywords: non-uniform factor of wind pressure; windage yaw; field measurement; wind load of transmission line
\end{abstract}

\begin{abstract}
Non-uniform factor of wind pressure is used to express distribution unevenness of wind pressure acting on the conductor at same time. USA, Japan and Germany etc developed countries have carried out many field measurement about it. Field measurement research in China is less, it is also found during actual operation that many flashover accidents were caused by windage yaw. In order to improve value accuracy of non-uniform factor of wind pressure, this paper formed a set of synchronous observation and measurement system for incline angle of the suspension string and the wind speed corresponding to the incline angle, which was referenced to field measurement method proposed by USA Electrical Science Research Institute. Based on field measured wind speed, the wind load of the whole span of the conductor was calculated. Based on field measured incline angle of suspension string, the wind load acting on the whole span was measured. By comparison of calculated wind load and measured wind load, the non-uniform factor of wind pressure of transmission line corresponding to field environment.
\end{abstract}

\section{Preface}

Because space distribution scope of the conductor is great, wind speed which acts on the conductor at same time is impossible to be consistent completely, unevenness is more and more obvious following increasing the span. Therefore non-uniform factor of wind pressure is applied in the power industrial specification to calculate wind load on the conductor, which is used to express distribution unevenness of wind speed [1]. Actual operation expression shows taking value of wind pressure non-uniform factor without support of actual measured data is liable to generate deflection. Small value is liable to cause more windage yaw discharging accident, great value will increase construction cost.

Because a large quantity of actual measured data for long term are short, there is many doubt on taking value of non-uniform factor during design. In DLT5154-2012 Design Technical Regulation of Overhead Power Transmission Tower Structure [2], non-uniform factor of wind pressure is decreased following increasing of wind speed. When wind speed is greater than $31.5 \mathrm{~m} / \mathrm{s}$, value is taken as 0.61. Regulation about taking value of wind pressure non-uniform factor in GB50545-2010 Design Specification of $110 \mathrm{kV} \sim 750 \mathrm{kV}$ Overhead Power Transmission Line[3], change of following the horizontal span $\mathrm{LH}$ is considered, non-uniform factor of wind pressure is back-calculated based on formula $=0.50+60 / \mathrm{LH}$. It is found during actual operation that value of 0.61 had caused several windage yaw flashover accidents in the $500 \mathrm{kV}$ power transmission line managed by State Grid Corporate in summer of 2004 [4].

USA Electrical Science Research Institute measures incline angle of the suspension string and weight of the conductor on base of the incline angle measurement instrument of the conductor suspension string, and back-calculates actual wind load acting on the conductor [5]. And obtain apparent wind load acting on the conductor according to spatial wind speed data of multiple points measured by the anemoscope, ratio between actual wind load and apparent wind load is non-uniform factor of wind pressure. This paper sets up a set of synchronous observation and measurement system 
for deflection angle and wind speed of the suspension string in reference to this actual measurement and data processing method, and apparent wind load acting on the whole span of the conductor is calculated based on actual measured wind speed, and actual wind load acting on the whole span of the conductor is calculated, actual measurement value for non-uniform factor of wind pressure is obtained by ratio between them.

\section{Field measurement plan and system installation at site}

Field measured length of the span is $290 \mathrm{~m}, 8$ measurement points are arranged along the whole span of the conductor in total, and span between measurement points is shown as figure 1 . The steel bar which is used to simulate the suspension string of the conductor is installed at 6\# measurement point, and the inclination measurement instrument is fixed on it. The steel tube rod with height of $20 \mathrm{~m}$ is set up at every measurement point, and the ultrasonic wind speed meter is fixed on it. Left side of the conductor is fixed on floor through the floor anchorage, so as to eliminate unbalance horizontal force of the whole span of the conductor.

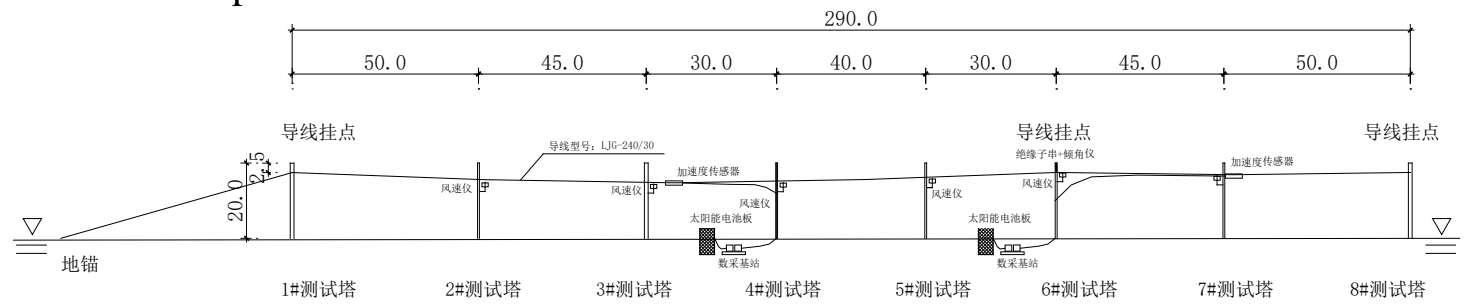

Fig.1 Vertical arrangement figure at field measurement point (unit of size in figure: $\mathrm{m}$ )

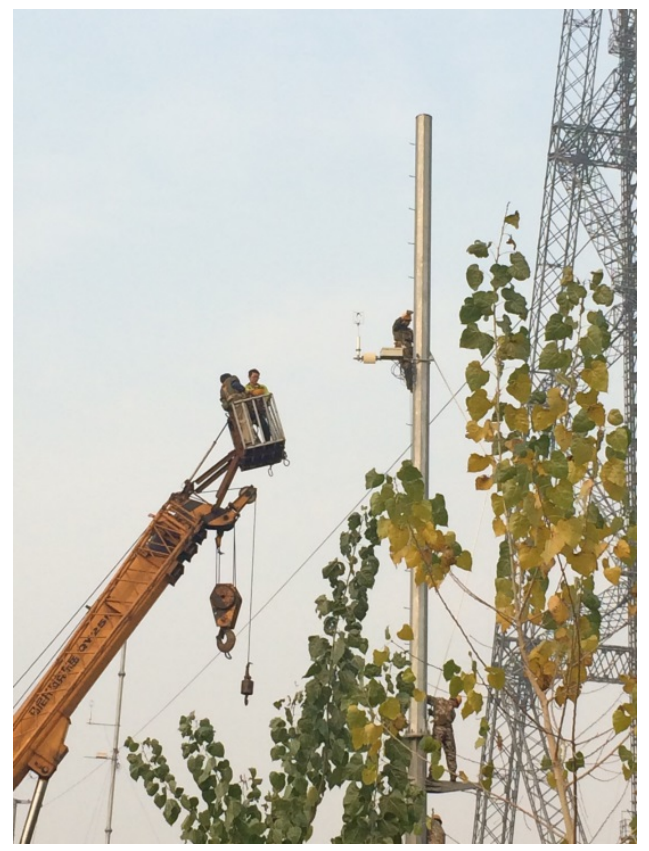

(a) Install wind speed meter

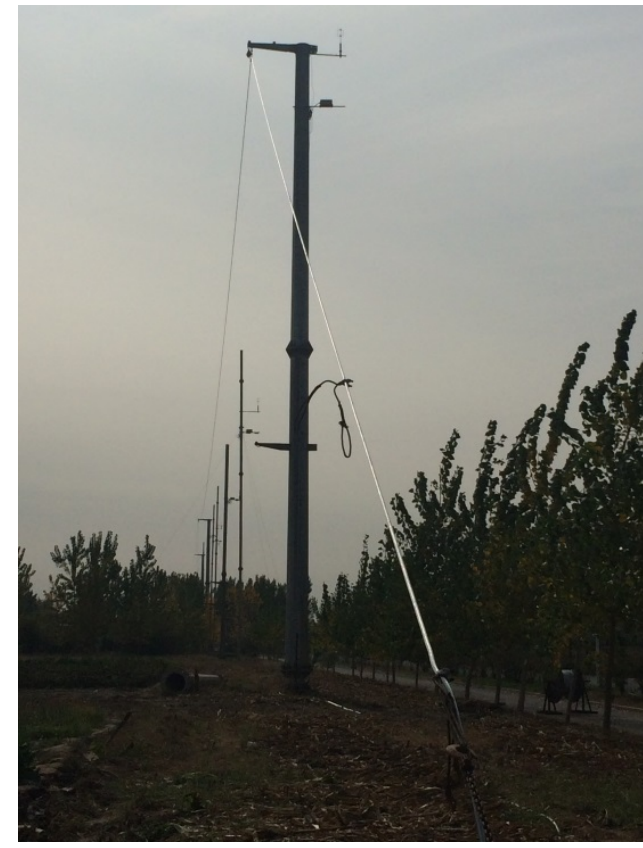

(b) Hang conductor 


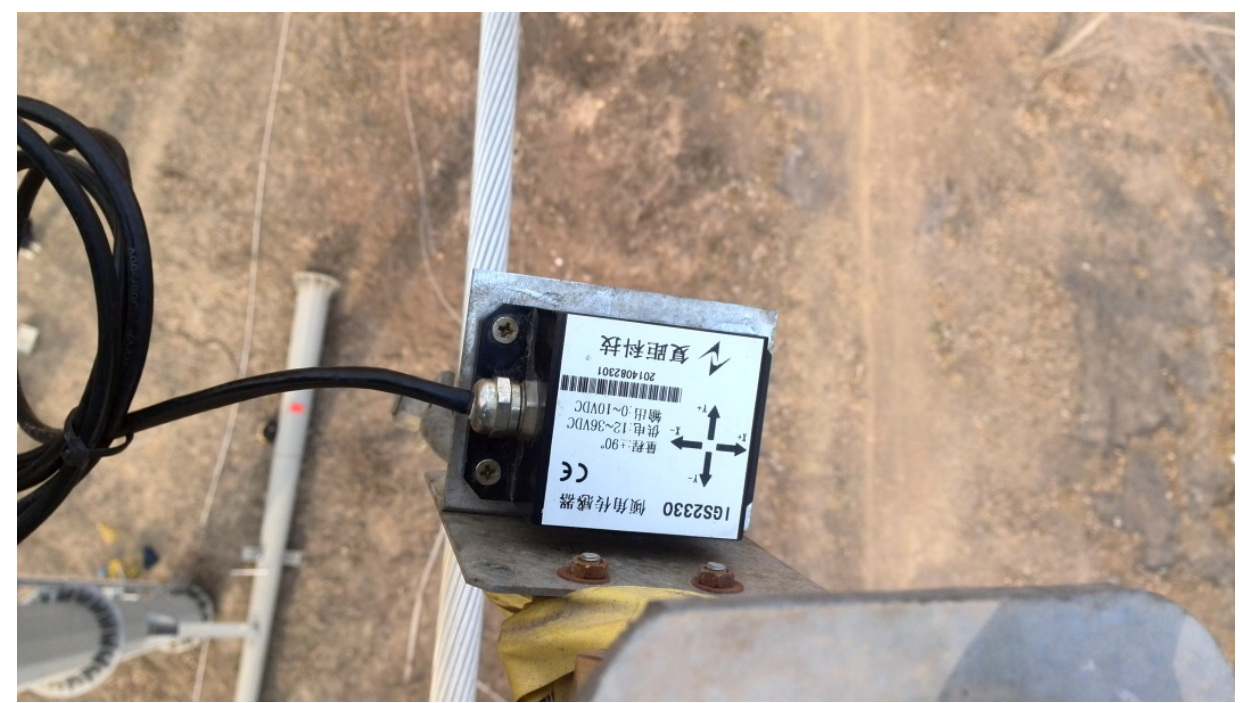

(c) Double angle deflection angle measurement instrument

Fig.2 Incline angle and wind speed synchronous observation and measurement system of whole span of conductor

Because spatial relativity field measurement of pulse wind is carried out in this project, common mechanical wind is only applied to measure average wind for $10 \mathrm{~min}$, which can't meet field measurement requirements. Therefore the supersonic wind speed meter must be applied. The selected supersonic wind speed meter is Master Pro III type supersonic wind speed meter manufactured by British Gill Company. This supersonic wind speed meter has the sampling frequency of maximum $32 \mathrm{~Hz}$, measurement scope of wind speed is $0 \sim 45 \mathrm{~m} / \mathrm{s}$, which meets with requirements on developing spatial relativity of pulse wind.

Incline angle of the suspension string is measured by the incline angle instrument. The applied incline angle instrument is IGS2330-45 type double axle deflection angle sensor, this sensor can carry out double axle synchronous measurement, maximum measurement angle is $\pm 90^{\circ}$, maximum resolution is $0.001^{\circ}$, horizontally installed and working temperature is $-40^{\circ} \mathrm{C} \sim 85^{\circ} \mathrm{C}$.

The whole set of the observation and measurement system is installed according to the planned field measurement plan (as shown in figure 2).

\section{Selection of effective sample}

Learn from installation position picture of the incline angle instrument, component at $\mathrm{x}$ direction is coincided with transversal line of the line, the collected deflection angle data are deflection angle of the conductor under wind load action. Because current field measurement data are limited and sufficient wind speed is needed to collect the sample. Otherwise, it is difficult to overcome static friction force between the suspension string and the hang point of the cross point, and effective incline angle data can't be collected. Take figure 3 as sample, the real effective data only include a small section in the figure within 24 hours incline angel signal in a day. In order to reduce working quantity for data processing, firstly review the incline angle data, and take data greater than deflection angle of $1.5^{\circ}$ to analyze. Similarly, wind speed shall take wind speeds at 6 points within corresponding time section. Similar effective sample is very less within the whole observation period. The samples within two most reasonable time sections are taken to analyze. First time section is from 7:00 AM in November 6, 2014 to 12:00AM in November 6, 2014, average value $\bar{\theta}$ of effective incline angle within this time section is $2.037^{\circ}$. Second time section is from 15:30PA in November 6, 2014 to 17:30 in November 6, 2014, and average value of effective incline angle within this time section is $1.802^{\circ}$. 


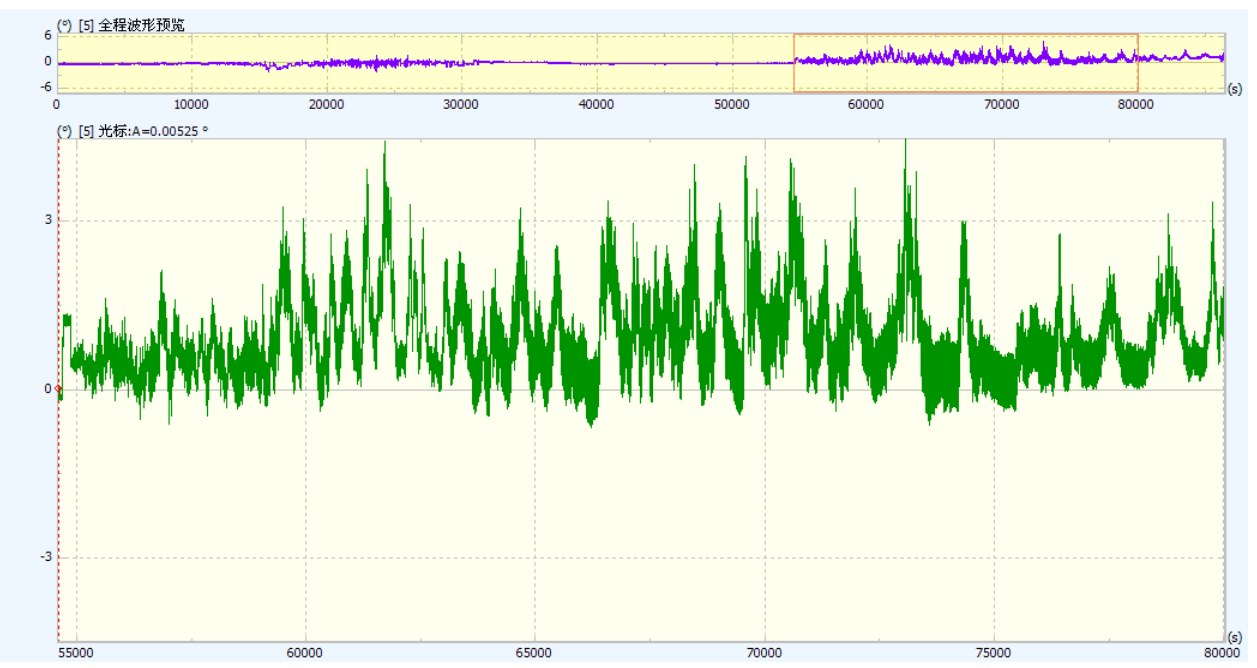

(a) Whole process review of incline angle field measurement data and selection of effective sample time section in November 5, 2014

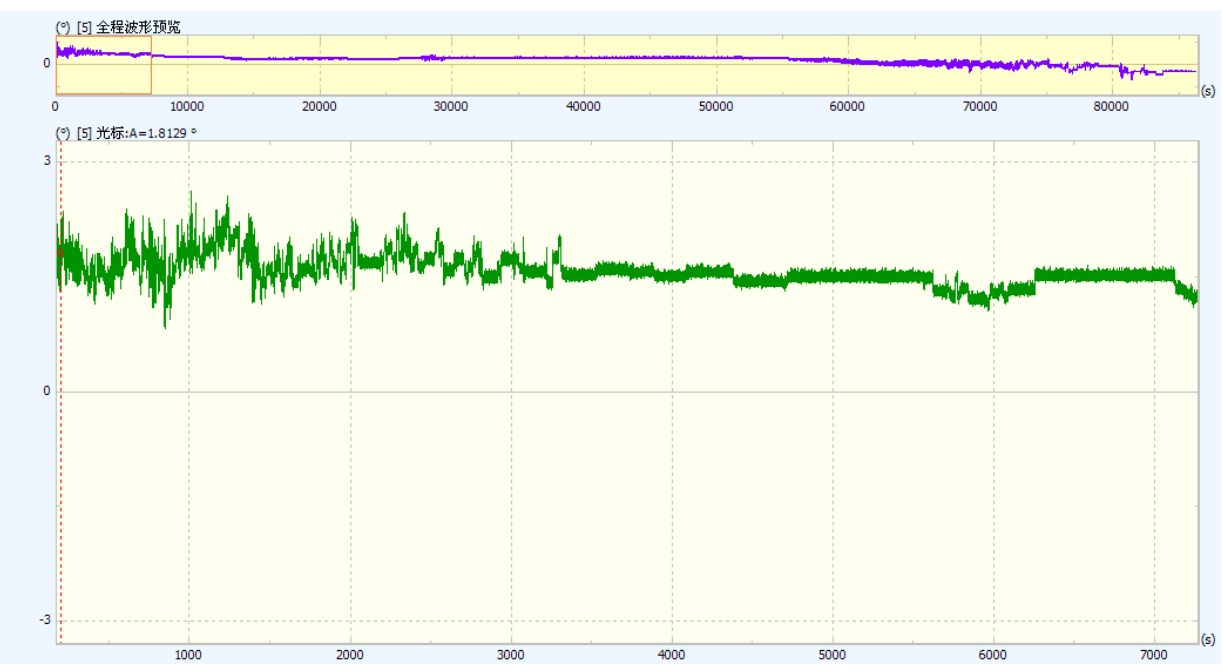

(b) Whole process review of incline angle field measurement data and selection of effective sample time section in November 6, 2014 Fig.3 Selection of effective sample

Average wind speeds within these two time sections are very stable, and wind speed at every measurement point vertical to conductor direction is shown as figure 1.

Tab.1 Average wind speed value at every measurement point within corresponding time section

\begin{tabular}{cccccc}
\hline Time section & $\begin{array}{c}U_{2} \sin \phi_{2} \\
(\mathrm{~m} / \mathrm{s})\end{array}$ & $\begin{array}{c}U_{3} \sin \phi_{3} \\
(\mathrm{~m} / \mathrm{s})\end{array}$ & $\begin{array}{c}U_{4} \sin \phi_{4} \\
(\mathrm{~m} / \mathrm{s})\end{array}$ & $\begin{array}{c}U_{5} \sin \phi_{5} \\
(\mathrm{~m} / \mathrm{s})\end{array}$ & $\begin{array}{c}U_{7} \sin \phi_{7} \\
(\mathrm{~m} / \mathrm{s})\end{array}$ \\
\hline $\begin{array}{c}\text { 2014-11-6-7: } 00 \sim \\
\text { 2014-11-6-12: } 00\end{array}$ & 3.83 & 3.70 & 3.40 & 4.05 & 4.34 \\
\hline $\begin{array}{c}2014-11-6-15: 30 \sim \\
\text { 2014-11-6-17: } 30\end{array}$ & 2.41 & 2.30 & 2.73 & 3.58 & 3.38 \\
\hline
\end{tabular}

\section{Calculation of non-uniform factor of wind pressure}

According to space position of actual wind observation and measurement point during second phase, its corresponding wind load calculation schematic figure is shown as following figure. 


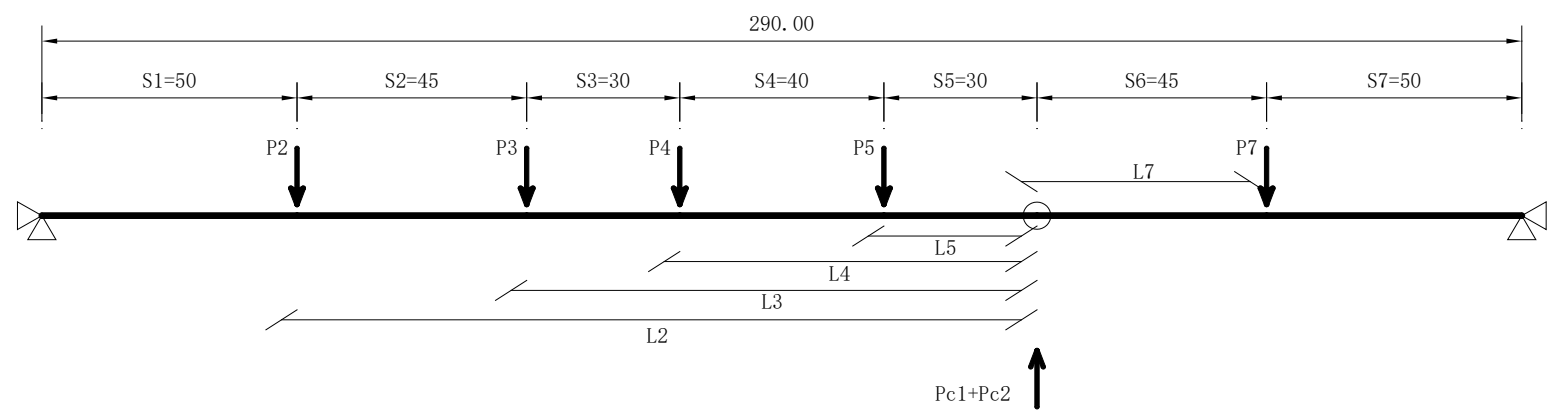

Fig.4 Wind load calculation schematic figure (size unit in figure: $\mathrm{m}$ )

Solution process of non-uniform factor of wind pressure is described in detail in following.

(1) Calculation wind load at single point

Calculation wind load at single point is calculated as following formula respectively:

$P_{2}=0.5 \rho\left(U_{2} \sin \phi_{2}\right)^{2} C_{d}\left(S_{1}+S_{2} / 2\right) D$

In which, $U_{2}$ is corresponding to average wind speed at measurement point $2, \phi_{2}$ is angle between wind direction corresponding to average wind speed at measurement point 2 and line direction of the conductor, $C_{d}$ takes value of 1.1 , conductor diameter of $D$ takes $0.0216 \mathrm{~m}, S_{1}$, taking value of $S_{2}$ is shown as figure 4 .

Similarly, calculation wind load formula at other single point is shown respectively as following:

$$
\begin{aligned}
& P_{3}=0.5 \rho\left(U_{3} \sin \phi_{3}\right)^{2} C_{d}\left(\frac{S_{2}+S_{3}}{2}\right) D \\
& P_{4}=0.5 \rho\left(U_{4} \sin \phi_{4}\right)^{2} C_{d}\left(\frac{S_{3}+S_{4}}{2}\right) D \\
& P_{5}=0.5 \rho\left(U_{5} \sin \phi_{5}\right)^{2} C_{d}\left(S_{4} / 2+S_{5}\right) D \\
& P_{7}=0.5 \rho\left(U_{7} \sin \phi_{7}\right)^{2} C_{d} S_{7} D
\end{aligned}
$$

(2) Calculation wind load of whole span of conductor

According to bending torque balance method, wind load of the whole span of the conductor is calculated according to actual space distance:

$$
\begin{aligned}
& P_{c 1}=\left(P_{2} L_{2}+P_{3} L_{3}+P_{4} L_{4}+P_{5} L_{5}\right) /\left(S_{1}+S_{2}+S_{3}+S_{4}+S_{5}\right) \\
& P_{c 2}=P_{7} \\
& P_{c}=P_{c 1}+P_{c 2}
\end{aligned}
$$

Wind load for single point is placed into above formula, calculate and the calculation wind load $P_{c}$ corresponding to two time sections are $63.01 \mathrm{~N}$ and $56.84 \mathrm{~N}$ respectively.

(3) Actual wind load of whole span of conductor

Diameter of LJG-240/30 conductor is $21.6 \mathrm{~mm}$, section area is $275.96 \mathrm{~mm} 2$, line density of the conductor is $0.9222 \mathrm{~kg} / \mathrm{m}$, elastic module is $73000 \mathrm{~N} / \mathrm{m} 2$, arc length of first span of the conductor is $205 \mathrm{~m}$ and slack is $2.75 \mathrm{~m}$, arc length of second span of the conductor is $95 \mathrm{~m}$, and slack is $0.62 \mathrm{~m}$, total weight of the conductor is $2711.3 \mathrm{~N}$, distribution weight of the middle suspension string $W_{d}$ takes value of $1355 \mathrm{~N}$.According to average value of deflection angle within corresponding time section. Place into formula (6) , obtain actual wind load $P_{m}$ within two time sections are $48.19 \mathrm{~N}$ and $42.58 \mathrm{~N}$ respectively.

$$
P_{m}=W_{d} \tan \bar{\theta}
$$

In which, $P_{m}$ is actual wind load of whole span of the conductor, $W_{d}$ is weight of the conductor and suspension string distributed at some one conductor hang point, $\bar{\theta}$ is average value of deflection angle of the suspension string within certain time interval. 
(4) Non-uniform factor calculation

The non-uniform factors of wind pressure which are finally determined are 0.765 and 0.749 respectively according to formula (7). It is basically approached to wind pressure non-uniform factor $(0.8)$ of the $200 \mathrm{~m}$ span in our country.

$$
\alpha=P_{m} / P_{C}
$$

\section{Conclusions}

This paper develops synchronous observation and measurement of wind speed and wind deflection angle of the conductor according to field measurement and analysis method of non-uniform factor forwarded by USA Electrical Science Research Institute, obtain wind pressure non-uniform factor at span condition of $195 \mathrm{~m}$ is basically approached to value in the specification of our country on base of field measurement data. But considering effective sample in the field measurement period is less, the relevant conclusion will be verified furtherly.

\section{References}

[1] Xu xiaodong, Wang Gang. Study on uneven wind pressure coefficient [J]. Power Construction, 2007, $28(07): 1-4$.

[2] Design technical regulation for overhead power transmission tower structure DL/T 5154-2012[S]. Beijing: China Power Press, 2012.

[3] Design code for $110 \mathrm{kV} \sim 750 \mathrm{kV}$ overhead power transmission line GB50545-2010[S]. Beijing: China Planning Press, 2010.

[4] Dong Xinsheng. Analysis on influence factors of wind deflection angle in Xinjiang power transmission line [J]. Xinjiang Power Construction, 2008, 2:1-3.

[5] EPRI's Transmission Line Mechanical Research Center. Evaluation of the results of several full-scale conductor wind loading experiments [R]. 207Coggins Drive, P.O. Box 23205,Pleasant Hill.1994. 